\title{
Biossociabilidades e políticas de governo no esporte de alto rendimento
}

DOI

http://dx.doi.org/10.11606/ 2179-0892.ra.2017.141650

\section{Ceorge Saliba Manske}

- Universidade do Vale do Itajaí | Itajaí, Santa Catarina, SC, Brasil

vgsmanske@yahoo.com.br

\section{RESUMO}

Tomando as Olimpíadas a serem realizadas em Tóquio em 2020 como ponto de partida para problematizações acerca do governo de atletas de alto rendimento, discuto neste estudo a construção de coletividades biossociais enquanto estratégias de controle de sujeitos e comunidades específicas. Parto do pressuposto de que as condições biotecnológicas hodiernas alteram as noções tradicionais entre natural, cultural e artificial, e que estas condições constituem aberturas para emergentes formas de regulação social, exemplificadas, neste caso, nos atletas e esportes de alto rendimento. $\mathrm{Na}$ condução dessas discussões analiso os modos pelos quais a Agência Mundial Antidoping (WADA-AMA) elabora e executa ações de gerenciamento da vitalidade esportiva, através, principalmente, dos excertos e enunciados presentes na revista Play True. Considera-se que as contemporâneas condições biotecnológicas de alteração do humano compõem novas formas de socialização, marcadas pelo incremento das capacidades vitais, alterando as compreensões tradicionais de corpo e natureza, exigindo novas formas de governo dos corpos. 


\section{DAS CONDIÇÕES CULTURAIS DO ESTUDO}

No intervalo entre os recentes Jogos Olímpicos de 2016 realizados na cidade do Rio de Janeiro e os Jogos Olímpicos de 2020 a serem realizados na cidade de Tóquio há, para a comunidade esportiva, de modo particular, e para a sociedade como um todo, de modo geral, especulações, práticas, interesses e curiosidades acerca dos possíveis alcances atléticos dos seres humanos, da superação de suas marcas, da transposição de barreiras, através não apenas dos seus esforços, mas, sobretudo, dos usos que fazem de aparatos tecnológicos, métodos e substâncias que aumentam sobremaneira suas performances esportivas. Assim, estabelece-se uma série de situações, possibilidades e acontecimentos vinculados ao desempenho atlético que precisam ser mapeados, regulados, direcionados e governados, com a justificativa tida como "universal" de que é necessário evitar que a trapaça ou o desrespeito às regras atinjam o tão proclamado espírito olímpico, que preza pela igualdade e honestidade nas disputas esportivas' ${ }^{1}$. Portanto, compete ao órgão máximo de controle e fiscalização das ações esportivas a garantia do cumprimento e efetividade desta regulação, a saber, a World Antidoping Agency - Agência Mundial Antidoping (WADA-AMA), entidade internacionalmente reconhecida pelo controle dos processos de dopagem entre os atletas de elite e alto rendimento.

A WADA-AMA é uma organização mundial baseada num modelo híbrido de gestão, sendo público-privada, pois é mantida tanto pelo Comitê Olímpico Internacional (COI) como pelos governos de diversos países do mundo. A WADA tem como missão "promover, coordenar e monitorar a luta contra o doping no esporte em todas as suas formas" (WADA-AMA, 2014). No cumprimento dessa missão a agência promove pesquisas científicas, projetos educacionais, desenvolvimento de capacidades na luta contra o doping e a elaboração e policiamento do Código Mundial Antidoping, com o intuito de, através de seus esforços, dar a oportunidade de tornar o esporte limpo de todas as artífices que vão de encontro aos ideais universais esportivos (WADA-AMA, 2014). Dito de outro modo, compete a WADA-AMA a confecção, exercício e controle de estratégias políticas de governo dos atletas e do esporte de alto rendimento.

Diante destes apontamentos que envolvem não apenas o esporte de al to rendimento e seus atletas, mas, principalmente, a realização de diversos megaeventos esportivos que difundem uma determinada cultura esportiva, torna-se não apenas possível como também necessário discutir os elementos circundantes a esse conjunto de ações, sujeitos e práticas, com implicações de toda ordem nos âmbitos social, econômico, político e cultural'2. Assim, proponho neste estudo problematizar as estratégias elaboradas e executas pela WADA-AMA no controle das ações de doping esportivo enquanto formas de agenciamento e
1 Não se está afirmando aqui que as ações empreendidas pelos órgãos reguladores do esporte de alto rendimento se engendram, de forma neutra, numa estratégia de pureza e limpeza das ações esportivas a serem policiadas. Aliás, Trabal (2013) apresenta informações relativas às concepções de agentes vinculados ao controle do doping em que estes afirmam basear suas ações muito mais no cumprimento de legislações e informações acerca do doping que numa indução a uma reflexão crítica sobre os preceitos que, teórica e ideologicamente, reformularam o esporte moderno a partir de Pierre de Coubertin. Assim, é possível discutir as ações de agências reguladoras não como estratégias direcionadas a uma "cruzada" pela moral do atleta ou seu desempenho esportivo, mas sim, como mecanismos regulatórios que se inserem num rol mais amplo em que o esporte de alto rendimento ou o esporte espetáculo estão assentados.

2 Acerca das inúmeras implicações que eventos como as Olimpíadas podem acarretar nos mais diversos segmentos e instâncias sociais vide: Legados de megaeventos esportivos, organizado por Nelson Carvalho Marcellino (2013); Megaeventos esportivos, legado e responsabilidade social, organizado por Katia Rubio (2008); a edição $n^{\circ} 41$ do periódico Motrivivência (UFSC) que tem como tema "Manifestações populares, Cidadania e Megaeventos esportivos", 2013; os Anais do XVII Congresso Brasileiro de Ciências do Esporte (CONBRACE) e IV Congresso Internacional de Ciências do Esporte (CONICE); e Megaeventos esportivos no Brasil: um olhar antropológico, de Arlei Sander Damo e Ruben George Oliven (2014). 
governo dos atletas de alto rendimento, analisando tais estratégias a partir das atualizações dos conceitos de governo e biopolítica de Michel Foucault elaboradas, especialmente, por Paul Rabinow e Nikolas Rose, conjuntamente com reflexões e estudos de autores que se filiam a tais perspectivas teórico-analíticas.

No que tange ao material analisado, utilizou-se a revista oficial da WADA-AMA, a Play True Magazine, que é citada como a publicação carro-chefe da agência, na medida em que melhor a representa e estabelece "uma análise profunda dos tópicos principais referentes à luta contra o doping realizada pela WADA" (WADA-AMA, 2014). Essa revista é publicada desde 2002, com periodicidade média quadrimestral-além dos números especiais e comemorativos-, com publicações em inglês desde seu início e em espanhol desde 2004. Nestes exemplares procurei identificar quais significados estavam presentes nos enunciados da revista quando tratavam de temas relacionados ao controle e regulação dos atletas de alto rendimento, enfatizando os efeitos que tais proposições podiam gerar enquanto estratégias de governo, sugerindo que estas conformam, ao fim, novas formas de coletividade entre os esportistas.

Cabe ressaltar que a revista funciona também como um "hipertexto" na medida em que, constantemente, cita, refere, indica e sugere outros documentos oficiais da WADA-AMA para consulta ou como referência, tal como o Código Mundial Antidoping. Esta revista foi entendida enquanto um artefato que materializa elementos culturais mais amplos, vinculados a uma comunidade específica, qual seja, os atletas de alto rendimento e o esporte de alto rendimento. $A$ Play True, portanto, configura-se enquanto um produto que descreve e constrói significados culturais específicos pertencentes a esse grupo de indivíduos, indicando trilhas a serem seguidas na compreensão de enunciados que constituem as realidades destes sujeitos e comunidade.

\section{A BIOSSOCIABILIDADE ENQUANTO ESTRATÉCIA DE GOVERNO}

Os atletas de elite carregam consigo a mesma condição ontológica de nós, não atletas (Welsch, 2001). Isso implica que as performances que esses conquistam podem até mesmo ser tomadas como nossas, na medida em que seus corpos têm correlação direta com os nossos, mediante a prerrogativa que ambos podemos ser tomados coletivamente como seres humanos (Welsch, 2001). No entanto, mesmo que sejamos incluídos numa mesma categoria de seres vivos -os humanos -, os atletas de al to rendimento têm características próprias que, embora ontologicamente não os singularizem, estabelecem enormes distanciamentos no que tange aos desempenhos físico-desportivos.

Muitos dos esportistas de elite se tornam (ou são tornados) atletas a partir de uma conformação ou característica biológica tida como natural (maior resis- 
tência muscular, maior flexibilidade, maior capacidade de impulso, etc.). Essa condição Ihes possibilitaria ter performances esportivas bem acima da média geral dos demais sujeitos. Esta forma de compreensão, que caracterizou indivíduos e os alocou em determinadas posições a partir de marcações biológicas, baseadas num essencialismo natural potencializado pelo treinamento, deixou de ser produtiva para analisarmos as condições contemporâneas em que elementos como o natural, o cultural e o artificial se confundem. Em suma, é numa perspectiva essencialista e naturalista de corpo que o esporte moderno se baseia para compreender seus atletas de elite. No entanto, frente às condições hodiernas das biotecnologias a plicadas ao esporte, é preciso reorganizar as formas de compreensão-e regulação-destes sujeitos.

Cabe ressaltar que as concepções e epistemologias que se apoiam em perspectivas naturalistas de mundo-e consequentemente de corpo-, que veem a distinção entre natureza e cultura e atribuem à primeira um caráter essencialista e universal, se apoiam, segundo Rabinow (1999), em alguns axiomas centrais. O primeiro é de que o artificial nunca é tão bom quanto o natural. Assim, toda e qualquer intervenção humana na natureza, seja na tentativa de imitá-la seja na tentativa de modificá-la, está sempre aquém do valor daquilo que já era dado, natural. Um segundo axioma, assinala o autor, vincula-se à noção de que a vida é autoprodutiva, ou seja, a natureza é que fornece a própria vida e sua contínua produção. Por fim, a ideia de homeostase, autorregulação, subentendida como a regra central para a continuidade da ordem natural do mundo, conforma o terceiro axioma. A própria ação humana não mais é tida como natural, a não ser que esse natural seja da ordem do significado da estimulação e expansão da própria vida humana (Rabinow, 1999).

Rabinow (1999), assim como Rose (2013), afirma que a melhor maneira para entendermos o momento atual de transformações das relações humanas e sociais com a natureza é identificarmos algumas recorrências ou efeitos em que tais transformações se manifestam. Rabinow (1998, apud Machado e Silva, 2008) também discute as alterações da compreensão de natureza e cultura a partir das análises da constituição de sujeitos e identidades seguindo os impactos sociais da biotecnologia. Para o autor, haveria na atualidade, pelo menos, dois tipos de relações sociais baseadas nas narrativas das tecnologias da vida, a saber, a sociobiologia e a biossociabilidade. Essas duas noções se constituiriam em possibilidades para compreendermos o momento atual da influência das biotecnologias nos modos de conceber o mundo e de nos relacionarmos nele.

No caso da primeira, a sociobiologia, as relações humanas e modos de pensar ainda estariam fortemente marcados pela ideia evolucionista de mundo, na qual a sociedade se organiza a partir de elementos e marcas fundamentalmente biológicas - tal como o esporte moderno e seu esportista, aqui inicialmente 
referidos. Desse modo, a constituição de grupos ou identidades pessoais estaria condicionada aos elementos biológicos constituintes dos sujeitos. A construção das identidades de gênero, por exemplo, a partir de marcas biológicas tais como presença ou ausência de pênis ou clitóris, seria um exemplo do modo como se opera nas sociedades ocidentais modernas a diferenciação e constituição de grupos e identidades como homem/mulher, macho/fêmea, atletas masculinos/ atletas femininos.

Já no outro caso, na biossociabilidade, o que estaria em pauta é a forma como a natureza é modelada na cultura (em contraste com sociobiologia em que a natureza organiza as relações sociais). Assim, para a biossociabilidade a natureza, além de ser conhecida, forjada e refeita pela cultura, através da técnica e da biotecnologia, ao mesmo tempo e de forma inextrincável, transforma a maneira pela qual conhecemos e experimentamos aquilo que era tido como cultural, ou ainda, numa perspectiva clássica de cultura, os bens ou conhecimentos tipicamente oriundos da produção humana.

Assim, na sociobiologia haveria uma primazia do biológico na organização das relações sociais, enquanto na biossociabilidade não existiria tal primazia, nem de ordem biológica tampouco cultural. Estas duas dimensões estariam, a partir das biotecnologias de vida contemporânea, interagindo na configuração de uma terceira via de relações sociais, em que as fronteiras entre cultura e natureza estabelecidas pelo pensamento moderno estariam borradas, compondo novas formas de experimentações sociais.

Nas palavras do próprio Rabinow (1999: 143-144),

se a sociobiologia é uma cultura construída com base numa metáfora da natureza, então na biossociabilidade a natureza será modelada na cultura compreendida como prática; ela será conhecida e refeita através da técnica, a natureza finalmente se tornará artificial, exatamente como a cultura se tornou natural. Se este projeto chegasse a ser realizado, el e seria a base para superar a separação entre natureza e cultura.

A artificialização da natureza sugerida por Rabinow (1999) incorporaria a construção de novas verdades oriundas dos saberes biotecnológicos, em especial dos projetos genômicos. A construção dessas verdades possibilitaria a formação de novas identidades e de grupos, dando margem a redes de socialização (biossociabilidade) marcadas pelos saberes biotecnológicos, artificiais.

Casos como o relatado por Fausto-Sterling (2001/2), em que atletas olímpicas mulheres até a década de 60 do século passado tinham que desfilar nuas perante um corpo de examinadores para certificar sua feminilidade não ocorreriam mais. Tal caso é emblemático para pensarmos a noção de sociobiologia, 
uma vez que somente as marcas (visíveis, palpáveis e universais) biológicas eram suficientes para determinar um grupo social, a saber, mulheres atletas olímpicas. No entanto, comenta a autora, tal modo de averiguação do sexo foi substituído por um teste mais científico, o da análise do cromossomo. Assim, o teste poderia mapear os genes das atletas e identificar pequenas regiões ou pares de cromossomos que pudessem ter a presença de hormônios masculinos. Casos como o da corredora espanhola Maria Patiño, que teve uma punição severa -a perda da medalha olímpica - por ter a presença de marcadores masculinos em sua constituição genética, caracterizada como síndrome de insensibilidade ao andrógeno, seriam mais facilmente mapeados (Fausto-Sterling, 2001/2). Analisando esta situação a partir da noção de biossociabilidade proposta por Rabinow (1999), não haveria somente competições entre atletas masculinos ou femininos, tal como no modelo tradicional de disputa olímpica, mas também entre atletas portadores de tal doença ou deficiência genética em determinado par de bases de cromossomo, ou, como no caso de Patiño, haveria uma categoria para "mulheres portadoras da síndrome de insensibilidade ao andrógeno" (Fausto-Sterling, 2001/2).

Atualmente podemos encontrar no seio da sociedade grupos que não apenas aceitam essa possibilidade de novas formas de sujeição e organização coletiva - através das biotecnologias contemporâneas -, mas que buscam incorporar tais formas de pensar e existir em suas maneiras de viver, através de outros processos de subjetivação. Penso estes grupos a partir da noção biossociabilidade, cunhada por Rabinow (1999).

Exemplos que se inserem na teia da biossociabilidade contemporânea podem ser trazidos a partir do princípio da transhumanidade, por exemplo. Existem grupos ativistas que advogam a favor da constituição de um novo tipo de ser humano, o "transhumano". Esses grupos se organizam e divulgam materiais na rede mundial de informações (internet), criando blogs ${ }^{3}$ e encontros presenciais para discutir possibilidades transhumanas de vida.

$\mathrm{Na}$ Carta de Princípios da Transhumanidade encontramos, por exemplo, manifestações que corroboram o argumento do desenvolvimento de novos grupos e novas subjetividades. Assim, objetivos tais como "ampliar o potencial humano de superar o envelhecimento, deficiências cognitivas, o sofrimento involuntário, e nosso confinamento no planeta Terra", ou ainda, defender "o uso de técnicas que podem ser desenvolvidas para ajudar a memória, concentração e energia mental", ou aprimorar "terapias de extensão da vida, tecnologias de escolha reprodutiva, métodos de criogenia", e outros que ampliem e aperfeiçoem o ser humano são amplamente descritos como finalidades e princípios dessa declaração (Humanityplus, 2015). Os argumentos de Sloterdijk (2006) acerca das possibilidades que a biotecnologia oferece ao ser humano para manipulação
3 Dentre os tantos movimentos criados e veiculados em blogs sobre o transhumanismo, é possível destacar o Humanityplus, órgão sem fins lucrativos que agrega "aproximadamente 6000 pessoas seguidoras do Humanity+ advindas de mais de 100 países, desde Afeganistão ao Brasil, do Egito à Filipinas". Disponível em http://humanityplus. org. Acesso em 02/07/2015. 
dele mesmo tornam-se evidentes quando analisamos alguns dos princípios da Declaração Transhumanista tais como os acima descritos.

No ano de 2010, por exemplo, ocorreu o evento H+Summit, na Universidade de Harvard. Esse evento foi organizado em dois dias de encontros, nos quais foram discutidos os potenciais tecnológicos para modificar corpos, mentes, vida e o mundo, advogando a ideia de que "a humanidade poderá transformar-se radicalmente pela tecnologia num futuro próximo" (Humanityplus, 2015). Outro exemplo de grupos organizados a partir desta nova configuração humana está claramente explicitado num dos princípios da Declaração da Transhumanidade. Nela está escrito o seguinte: "Precisamos também de fóruns onde as pessoas possam discutir de forma construtiva o que deve ser feito, e uma ordem social em que as decisões responsáveis possam ser implementadas" (Humanityplus, 2015). A construção desses grupos, fóruns de debate e encontros em torno do tema transhumanista representa a agregação e criação de grupos identitários em torno das novas possibilidades de sermos humanos no seio das tecnologias da vida contemporânea.

Com base nestes poucos exemplos já é possível perceber o quão pertinente é a reflexão de Rabinow (1999) quando ele apresenta a noção de biossociabilidade para designar grupos ativistas que se reúnem a partir das biotecnologias. Inclusive, arrisca o autor, "esses grupos terão especialistas médicos, laboratórios, histórias, tradições e uma forte intervenção dos agentes protetores para ajudá-los a experimentar, partilhar, intervir e entender seu destino" (Rabinow, 1999: 147). Não obstante, a organização Humanityplus possui parceiros, instituições apoiadoras, newsletter, publicações oficiais, além de consultores especialistas como biomédicos gerontólogos, cientistas políticos e diretores de empresas biotecnológicas (Humanityplus, 2014).

Os apontamentos apresentados por Rabinow (1999) auxiliam a pensar e analisar as novas configurações de grupos sociais ou de sujeitos a partir dos efeitos das aplicações biotecnológicos nos seres humanos. Em outro sentido, mas ainda sobre o mesmo tema, Rose (2013) concebe tais transformações a partir das interconexões que estabelecem com diversas dimensões sociais contemporâneas. Dentre essas dimensões destaco, nesse momento, a "molecularização".

Por molecularização Rose (2013) indica um modo particular de compreensão da vida, em que as ciências naturais e biomédicas concebem a vida e a vitalidade humana em níveis microscópicos, os quais podem ser manipulados e agenciados de diversas maneiras. Nessa ótica, a vida, compreendida enquanto codificações não visíveis a olho nu, está sob permanente acesso e intervenção humana. Desse modo, a visão de corpo baseada numa compreensão "molar" tem sofrido alterações na medida em que os avanços biotecnológicos criam possibilidades de conhecê-lo neste outro nível, "molecular", no qual as possibilidades de 
mapear e descrever o corpo são realizados a partir de elementos infinitamente menores. Assim, a vida é que sofre ações nos termos de propriedades funcionais do código sequencial genômico e em suas variações (Rose, 2013).

É possível percebermos a maneira pela qual este modo de pensar pode ser incorporado no esporte de alto rendimento, inclusive regulando modos de participação de atletas e determinando suas identidades (sujeitando-os), tal como o referido acontecimento da corredora espanhola Maria Patiño, citado por Fausto-Sterling (2001/2). O caso dessa atleta expõe o modo como se regulou, no âmbito esportivo internacional, a identidade de gênero da corredora a partir do nível molecular. Caso Patiño tivesse se submetido a um exame tradicional de verificação de sexo das competidoras, utilizado até meados da década de 60 do século passado, ela teria passado despercebida pelo exame de averiguação de feminilidade. Porém, ela teve que se submeter a um exame em nível molecular, no qual retiraram células de sua bochecha através do método de raspagem e identificaram a presença de um cromossomo $Y$ em sua constituição genética. Aliás, "seus lábios [vaginais] ocultavam testículos e, além disso, ela não tinha ovários nem útero" (Fausto-Sterling, 2001/2).

A regulação da participação de Patiño, assim como a determinação de seu sexo foram realizadas em nível molecular. Inclusive, tal averiguação também desencadeou outras observações como a presença de pequenos testículos e a ausência de ovário, marcas corporais que, tradicionalmente, não identificam uma mulher. Estas conclusões só puderam ser acessadas a partir de um conjunto de aparatos que permitem tais des-cobertas (algo que já estava lá, coberto, mas ainda não tinha vindo à tona).

Não obstante dessa linha argumentativa, Sibilia (2002: 77) relata a ascensão de um modo de pensar "informático-molecular" em detrimento do "mecânico-geométrico". Nesse novo "estilo de pensamento", a matéria prima da vida, seu enigma fundante, não está em nível molar, mas sim no nível da informação. Tal emergência de pensamento ocorreu a partir da "exploração da vida em escala atômica", o que resultou, posteriormente, numa "descoberta fundamental: a estrutura da molécula do DNA" (Sibilia, 2002: 75). De modo semelhante, Lima (2004) relata a superação do "corpo-máquina" pelo "corpo-informação", na medida em que a promulgada ideia e concepção de ser humano, baseado, sobretudo, na modernidade e na metafísica, têm sucumbido mediante as tecnologias contemporâneas.

Tomando a descoberta da molécula de DNA como um marco no princípio de inteligibilidade da vida a partir da informação genética, passamos, por assim dizer, a explorar, mapear e manipular a vida a partir de códigos de informação. Esses códigos, entrementes, não são visíveis em nível molar, tornando-se "visíveis" - e diria até mesmo possíveis de serem produzidos, em meio aos aparatos 
tecnológicos que lhe dão sustentação, tais como microscópicos e outros-em níveis moleculares. Assim, o nível molecular proposto por Rose (2013) se assenta, também, numa visão "informático-molecular", tal como citado por Sibilia (2002), e de "corpo-informação", aludida por Lima (2004). E mais: tal modo de pensar ganha força nas palavras de Sloterdijk (2006) quando ele trata das relações entre biotecnologia, homem e natureza a partir da noção de "princípios de informação".

Os caminhos de análise apontados pelos autores indicam pistas que foram seguidas na discussão do problema de estudo aqui proposto. As ideias aqui apresentadas servem para construir um panorama amplo do modo pelo qual as relações entre artificial e natural (Rabinow, 1999), entre modos de pensamento em nível molar e molecular (Rose, 2013) e princípios de informação (Sibilia, 2002; Sloterdijk, 2006; Lima, 2004) podem auxiliar a compreender a emergência e configuração de uma forma particular e contemporânea de compreensão da vida e do humano, e nesse caso no que concerne aos atletas de al to rendimento, de novas formas de socialização, a saber, as coletividades biossociais.

\section{ESTRATÉCIAS DE GOVERNO DOS ATLETAS DE ALTO RENDIMENTO}

Na esteira dos processos formativos da WADA-AMA para os atletas a ela submetidos, o Programa de Conscientização ocupa um dos lugares mais centrais das ações empreendidas. Dentre os principais objetivos preconizados, a conscientização dos atletas em "quem nós somos e quem queremos ser" torna-se uma das razões centrais desse programa, indicando os tipos de ações e comportamentos esperados dos sujeitos que são e virão a ser os esportistas de elite (WADA-AMA, 2002: 5). Para tanto, este programa "é alocado em áreas de intenso movimento de atletas nos eventos esportivos (por exemplo: o salão de janta dos atletas, a zona mista internacional ou nos centros esportivos)". Nestes espaços, há a exibição, através de banners, laptops e outras ferramentas dos principais valores e ações da WADA-AMA. Trabal (2013: 12) remonta também a esses aspectos quando evidencia que "as mensagens contidas nos testes de conhecimentos, cartazes e outros instrumentos de prevenção visam, mais ou menos explicitamente, a atenuar um suposto déficit de informações" na condução das ações realizadas por parte dos atletas. Assim, é com a intenção da condução das possibilidades de ações a serem tomadas pelos atletas submetidos à Agência que as práticas propostas pela WADA se articulam. Estas orientações sobre um eventual campo de ações conformam formas de subjetividades esportivas que, em seu conjunto, configuram coletividades específicas.

Em linha com essas observações, Rose (2001: 34) indica uma necessária preocupação "com as práticas pelas quais as pessoas são compreendidas e pelas 
quais se age sobre elas", que podem ser analisadas em diferentes dimensões, como a problematização, as tecnologias, as teleologias, as autoridades e as estratégias que incidem sobre os sujeitos. Embora distintas entre si, elas apresentam um eixo condutor comum, qual seja, o da "arte de governo". Rose (2001: 41) ainda salienta: "cada uma dessas direções de investigação é inspirada, em grande medida, na obra de Michel Foucault. Em particular, obviamente, elas surgem das sugestões de Foucault concernentes à genealogia da arte do governo".

O termo governo, para Foucault, refere-se às práticas destinadas aos "modos de ação mais ou menos refletidos e calculados, porém todos destinados a agir sobre as possibilidades de ação dos outros indivíduos" (1995: 244), as quais estão implicadas com: a) os modos como os indivíduos e grupos se posicionam no mundo e passam a entender e dar significados às coisas; b) os modos pelos quais indivíduos e grupos tornam-se sujeitos específicos de poder; c) os modos pelos quais populações tornam-se governáveis. Desse modo, governo é "entendido no sentido amplo de técnicas e procedimentos destinados a dirigir a conduta dos homens". Há, nesse "sentido amplo", diferentes formas de governo, sejam elas "das crianças, das almas, das consciências, de uma casa, de um Estado ou de si mesmo" (Foucault, 1997a: 101).

As formas de governo, compreendidas como atos de conduzir as ações dos outros, ou de "estruturar o eventual campo de ação dos outros" (Foucault, 1995: 244), indicam uma "perspectiva a partir da qual se pode tornar inteligível a diversidade de tentativas por parte das autoridades de diferentes tipos para agir sobre as ações dos outros em relação a objetivos" dos mais diversos (Rose, 2001: 41).

A afirmação antes destacada pela WADA-AMA, de que os atletas devem se reconhecer em sujeitos de um mesmo grupo é análoga ao preceito socrático do "conheces a ti mesmo", discutido por Rose (2013) como produtor de formas de coletivismo, na direção de práticas de governo. As novas formas de coletivismo debatidas por Rose (2013: 205) apresentam "circunstâncias onde as formas de vida, os compromissos éticos, os tipos de políticas e as tecnologias de comunicação" assentam as bases para que tais coletividades sejam possíveis. Assim, nessas coletividades o indivíduo não é uma parte isolada do grupo, mas é, ao mesmo tempo, representante e representado, são comunidades coletivas em que os sujeitos podem e devem ser responsáveis e portadores de seus discursos. Essa condição de pertencimento a um grupo é um dos investimentos da WADA-AMA quando incita os atletas a pertencerem a um grande grupo social, a saber, os atletas de elite, e que possam também incluir seus pares nesse mesmo grupo.

$\mathrm{Na}$ esteira da conformação dessas coletividades através de tecnologias de informação Trabal (2013), em sua pesquisa acerca das compreensões do doping por parte de atletas, valeu-se de fóruns da internet relacionados a esportes, nos quais os participantes poderiam relatar suas opiniões sobre o doping. Desse 
modo, as possibilidades de compreensão dos sujeitos acerca do "verdadeiro e o falso, o real e o possível de suas práticas", assim como, as relações estabelecidas entre o virtual e o real na produção de argumentos, experiências e verdades, conduziam a conformação de grupos e coletividades em torno do mesmo interesse, incluindo aí relações éticas de si para consigo e em relação ao outro. Tais registros indicam formas virtuais de construção de agrupamentos em torno do tema doping, e direcionam maneiras de relacionar-se consigo num espectro do que é possível e não possível àquele grupo. Não obstante, são extensões das práticas também realizadas pela WADA-AMA.

Dentre outros exemplos enquanto ações de governo direcionadas à coletividade biossocial dos atletas de elite é possível citar uma das principais ações da WADA-AMA (se não a principal), qual seja, o Código Mundial Antidoping. Na preparação de sua implantação, em 2002, foram realizadas ações de integração em conjunto com uma série de órgãos, tais como federações internacionais, comitês olímpicos, organizações governamentais, autoridades públicas e outros. O principal objetivo desses esforços em conjunto era o de criar não apenas o Código Mundial Antidoping (embora essa fosse a materialização dos esforços), mas, sobretudo, unir diferentes frentes, instituições e ações sob um guarda-chuva geral, que desse conta de representar toda a campanha antidoping em nível mundial. Era necessário um estandarte da WADA-AMA que fosse aceito e homologado por diversas partes interessadas. A esse documento deu-se 0 nome de Código Mundial Antidoping e a esses esforços de homogeneização e uniformização das ações atribuiu-se o nome de harmonização (WADA-AMA, 2002, n. 1: 13). No desenvolvimento da estrutura do Código Mundial Antidoping, uma das principais ações estabelecidas residia justamente na planificação de uma "harmonização universal", que contemplasse os principais tópicos da luta antidoping. (WADA-AMA, 2002, n. 1: 14). É preciso salientar que tais esforços vão na direção, principalmente, de uma tentativa de regulação universal das ações desportivas relacionadas ao doping, em virtude de ações que busquem uma homogeneização das práticas de desempenho esportivo, na medida em que desta forma o exercício de governo é mais acessível.

A perspectiva de uma política geral de harmonização acerca do doping no esporte não é uma ideia recente. Miah (2008: 63, destaques do original) ressalta que "a ideia da abordagem harmonizante ao (anti) doping tem sido associada à governança do esporte desde quase seu início, no começo da década 1960", mas somente na atualidade tem tomado contornos mais claros. Reitera ainda que $o$ principal argumento da política de harmonização é "garantir que muitas instituições esportivas estejam em concordância sobre os métodos de teste e sancionamento" (2008: 63). Entrementes, estas políticas sofreram com discordâncias entre governos e instituições esportivas durante muitos anos, e a criação da WA- 
DA-AMA em 1999 veio justamente para dar conta de superar esses obstáculos. Cabe ressaltar, por exemplo, na esteira dos diferentes interesses que subsidiam ações de harmonização mundial como esta, que, em virtude de prerrogativas e conveniências próprias, vinculadas às possibilidades de regulação de uma determinada prática esportiva, a Federação Internacional de Futebol (FIFA) relutou durante anos para ser signatária da WADA-AMA, incluindo sua participação a partir de 2006, apenas.

Exemplos dessa política de harmonização são inúmeros na revista Play True, especialmente na seção do glossário. Neste espaço são apresentados termos comuns que permeiam a WADA-AMA e que devem ser compreendidos pelo leitor, sendo, por isso mesmo, destacados na revista, na medida em que assumem importância nas ações da agência. No glossário de uma das primeiras edições da revista é apresentado um grande parceiro da WADA-AMA na cruzada antidoping o International Intergovernamental Consultative Croup on Anti-Doping in Sports (IICCADS). É uma instituição, como o próprio nome sugere, intergovernamental, presente em mais de 25 países, sediada na Austrália e fundada em 1999. Em parceria com a WADA-AMA, procura "encorajar o desenvolvimento regional de sustentação de associações intergovernamentais ou arranjos específicos para o antidoping" (WADA-AMA, 2002, n.2: 5). Nesta tarefa, em parceria com a WADA-AMA, procura coordenar participações governamentais no mundo, na tentativa de "facilitar a harmonização de políticas em áreas de responsabilidade e jurisdição exclusivas de governos" (WADA-AMA, 2002, n.2: 1). Assim, através de processos de regulação intergovernamentais no esporte em diferentes esferas internacionais, a harmonização das políticas antidoping toma a forma de estratégias, princípios e ações comuns em nível global. Eis a tarefa da harmonização: formar uma coletividade social a partir de agenciamentos sobre o doping que atinjam o escopo internacional, através de mecanismos regulatórios cada vez mais sofisticados, em que nenhuma esfera vinculada ao esporte e referida ao doping possa ser deixada de fora. Tais ações conformam, desde a construção de posições de sujeitos a serem ocupadas pelos atletas de alto rendimento em seu conjunto, coletividades biossociais. Além da IICCADS, em outro glossário da revista é citada a Concerted Action in the Fight against Doping in Sport (CAFDIS). Este programa foi criado em 2001 e é financiado pela Comissão Europeia, e consiste "na criação e suporte de um website com informações antidoping", tendo como principais parceiros comitês olímpicos internacionais, federações internacionais e nacionais, laboratórios credenciados e outros.

Um marco fundamental nos processos de harmonização das políticas antidoping foi a Conferência Mundial de Doping no Esporte, que precedeu a confecção do Código Mundial Antidoping, realizada na cidade de Copenhague, Dinamarca, em março de 2003, com a presença das mais diversas representações e autorida- 
des vinculadas ao esporte mundial. Esta conferência recebeu uma edição temática exclusiva da revista Play True (WADA-AMA, 2003, n. 1), que apresentava os principais pontos de destaque do célebre evento. $O$ principal objetivo da conferência foi discutir, aceitar e aplicar políticas para a implantação do Código Mundial Antidoping, resultando ao final do evento na publicação da resolução que aceitava o Código Mundial Antidoping. Ao final, estava delineada a conquista e materialização do principal objetivo da WADA-AMA: "Pela primeira vez todos os atletas irão participar sob as mesmas regras, as mesmas normas e as mesmas sanções para as regras antidoping". Ao final, esta conferência "remeteu uma poderosa mensagem aos trapaceadores: seus dias estão contados" (WADA-AMA, 2003, n. 1:1).

Esta espécie de cruzada em prol de uma pureza esportiva, baseada nas tecnologias, é referida por Trabal (2013: 32) enquanto "maneiras de convocar o futuro [que] começa por se impor", numa lógica de antecipação de riscos e, especialmente, de ameaças. Segue o autor: "para criar um perigo e, portanto, lançar um alerta, é preciso anunciar um futuro (geralmente sob a forma de profecia) e, ao mesmo tempo, considerar as modalidades para evitar esse perigo: a vigilância, a urgência e o prazo (...)". Nesse ínterim, a WADA-AMA ao alertar aos trapaceadores que seus dias estão contados não apenas exerce um poder de governo sobre as ações futuras destes, através de ameaças, mas ocupa um lugar específico e central no plano das coletividades a ela subjugadas, qual seja, a de soberania. Assim a WADA-AMA não apenas regula as ações dos atletas ou de uma determinada coletividade, mas impõe, controla, vigia, pune, em suma, é não apenas parte, mas detentora das relações de poder que se exercem nessa coletividade. $A$ WADA-AMA ao mesmo tempo compõe e dita as regras, as formas de vigilância e os mecanismos de punição. É parte integrante desta rede de biossociabilidade.

É neste ínterim que a política de harmonização proposta pela WADA-AMA atua, buscando minimizar as enormes discrepâncias que constituem os governos políticos, as federações nacionais de esportes e as próprias práticas esportivas nos diferentes redutos do planeta. Desse modo, embora seja uma reconhecida instituição de controle esportivo internacional, muitas vezes não possui alcance suficiente para gerir as distâncias e diferenças existentes nos esportes e nos setores de governos onde estes ocorrem. Na tentativa de suprir estas lacunas, elenca estratégias para adentrar cada vez mais em espaços antes não reconhecidos.

Em 2005, por exemplo, à WADA-AMA foi solicitada que desempenhasse um papel consultivo na Convenção Internacional contra o doping no Esporte da Unesco. As proposições finais desta convenção "foram ratificadas por mais de 125 dos 193 Estados Membros da Unesco (que representa quase $90 \%$ da população mundial)" (WADA-AMA, 2009, n. 2: 6). Desse modo, mesmo que tenha como filiados as mais diversas instituições esportivas internacionais e governos de boa parte dos países, quando há espaços em que as políticas de harmonização não 
conseguem adentrar, a criação de parcerias com órgãos supranacionais torna-se uma alternativa produtiva no alcance dessas metas.

A constituição de uma rede ampla que congrega um sem fim de associações e entidades nacionais, internacionais e até mesmo supranacionais, tal como descrito enquanto ações da WADA-AMA, vai na direção de compor uma teia ampla de efetivação não apenas de mecanismos reguladores contra o doping, mas também na construção e reforço de identidades coletivas baseadas em pressupostos biológicos, culturais e, quiçá, artificiais, como o caso do doping e de seus aprimoramentos da performance esportiva. Rose (2013) destaca que uma das decorrências das construções de coletividades biossociais é a materialização de associações, organizações e entidades que representem os cidadãos biológicos inscritos em determinadas marcas (no caso deste estudo, o uso de doping), tal como a WADA-AMA. Normalmente, descreve o autor, os serviços prestados por essa amálgama de instituições incluem informativos, publicações, programas, aconselhamentos, aportes jurídicos, entre outros, tal como ilustrado a partir do material da WADA-AMA.

Para além desta teia de relações - e, pelo contrário, compondo mais ainda estas formas de regulação de modo a estender o controle sobre o doping nos mais variados recônditos do planeta -, a WADA-AMA solicitou à International Police Organization (Interpol), reconhecida organização internacional de polícia, que a auxiliasse na condução dos aspectos de policiamento acerca do doping. Desde 2004, a partir de uma reunião na sede da Interpol, em Lyon (França), em que estiveram presentes representantes do Comitê Olímpico Internacional, da WADA-AMA e da Secretaria Geral da Interpol, ficou definida uma parceria no combate ao tráfico de substâncias possivelmente utilizadas para o doping. Nesta ocasião foi firmada uma parceria que resultou "numa rede de Oficinas Centrais Nacionais da Interpol em cada um dos 186 países membro da WADA-AMA, um sistema de comunicação de base de dados policiais global e seguro, que possam ser utilizados para localizar pessoas e redes" relacionadas ao doping (WADA-AMA, 2007, n.1: 4). No bojo destas relações não apenas as políticas de harmonização tomam forma, mas as de policiamento - neste caso criminal-compondo formas de regulação cada vez mais amplas e precisas. Tais estratégias se desenvolvem como formas de governo dos atletas, e mais, formas de governo da vitalidade esportiva, na medida em que buscam exercer o controle daquilo que viria a ser a potencialização do atleta. É neste escopo que emerge a noção de biopolítica aqui sugerida, enquanto uma política da própria vida, pois, diferentemente da "biopolítica tradicional" não atua apenas no controle dos processos de vida/morte ou saúde/doença, mas opera no controle da vitalidade da performance, do "mais", na regulação de uma coletividade que pretende incrementar as próprias capacidades vitais, num processo de governo de si e dos outros.

Uma dessas frentes de problematização nas quais o governo dos corpos se 
desenvolve é aquela voltada à vida dos sujeitos, tomando-os enquanto um "conjunto de indivíduos de uma mesma espécie". A este tipo de poder e de exercício de governo Foucault denominou de biopoder $(1988,1995,1997 a, 1997 b)$. Para Foucault (1988, 1997a, 1997b), o biopoder agia em duas frentes distintas: uma centrada diretamente nos corpos dos indivíduos, denominada de anátomo-política dos corpos, com viés disciplinar e individualizante, e outra que os concebia, enquanto conjunto, em um coletivo de indivíduos de um mesmo grupo (tomados como suscetíveis aos mesmos tipos de regularidades, ou seja, como uma espécie), denominada de biopolítica. Para os objetivos deste estudo, o eixo da biopolítica é mais útil analiticamente, visto que é este polo do biopoder que está vinculado à multiplicidade dos indivíduos enquanto pertencentes a um mesmo grupo.

Embora Foucault tenha explorado esta compreensão de governamento no contexto da discussão acerca da biopolítica, para mapear as transformações ocorridas na Europa entre os séculos XVII e XIX, e do biopoder, como um novo tipo de poder relativo às forças biológicas características de uma população, ambos os conceitos - apesar de centralmente importantes às análises acerca dos modos de governo - tornaram-se, de algum modo, limitados para dar conta das novas transformações ocorridas no âmbito das racionalidades e tecnologias de governamento dos corpos contemporâneos. É, portanto, neste nível de investimentos que situo as racionalidades e tecnologias de governo nas quais a WADA-AMA se insere e faz parte, ao mesmo tempo em que busca conhecer e intervir.

Com essa premissa Rabinow e Rose (2006) procuram discutir os diferentes usos dos conceitos de biopoder e biopolítica utilizados na literatura contemporânea e os modos como Foucault os operou analiticamente em suas obras, indicando, ainda, que foram conceitos não muito sistematizados pelo próprio Foucault, carecendo, assim, de maiores investimentos e esclarecimentos conceituais. Nesta direção, esses autores destacam que

na tentativa de fazer um diagnóstico a partir "do meio", pensamos que o conceito de biopoder direciona nossa atenção em três elementos chave que estão em jogo em qualquer transformação: o conhecimento de processos de vida vitais, as relações de poder que adotam os humanos como seres vivos como seu objeto, e os modos de subjetivação a través dos quais os sujeitos atuam sobre si próprios qua seres vivos, assim como suas múltiplas combinações (Rabinowe Rose, 2006: 53)

Na esteira desses apontamentos, e baseados em suas produções recentes, Rabinow e Rose (2006: 29) assumem "que os conceitos foucaultianos de biopoder e biopolítica mantêm consideráveis utilidades analíticas", mas que seria pertinente, ao utilizar tais conceitos no plano da atualidade, incluir alguns novos elementos, como as coletividades biossociais. 
Tal deslocamento e atualização da noção clássica foucaultiana de biopoder é também desenvolvido por distintos autores em suas pesquisas, conforme aqui já aludido (Fraga, 2006; Lima, 2004; Sibilia, 2002). Lima (2004), por exemplo, ao analisar as transformações hodiernas relativas à produção do corpo, ressalta que as novas modalidades de poder-saber operam na direção de um corpo compreendido enquanto informação, especialmente pelo DNA. Em sintonia com as argumentações que tenho elencado, o autor segue na direção do que propõe Rose (2013), com "molecularização", e Sloterdijk (2006), com "princípios da informação". Não distante disso - aliás, na mesma direção-, Sibilia (2002) também analisa o projeto fáustico do homem a partir dos princípios informacionais. Fraga (2006), por sua vez, analisa os modos de governo contemporâneos dos corpos no "mercado da vida ativa" através do que ele denomina biopolítica informacional, na medida em que as estratégias por ele analisadas compõem redes de informações para que os sujeitos cuidem de suas saúdes através de um estilo de vida ativo.

Embora não sejam abundantes, estudos vêm sendo realizados na direção de atualizações da noção de biopoder e de biopolítica foucaultianos, sobretudo aqueles voltados aos novos investimentos nos corpos (Lima, 2004; Sibilia, 2002), passando por análises dos aspectos de saúde e, também, da cultura física e esportiva de modo geral (Fraga, 2006). Obviamente, os suportes teórico-metodológicos de Rose (2013), Rabinow (1999) e Rabinow e Rose (2006) marcam iniciativas mais amplas sobre estes aspectos. Há também estudos que desenvolveram análises sobre a WADA-AMA a partir da noção de governo e biopolítica foucaultianos, porém, mantendo os conceitos tal como aqueles elaborados originalmente por Foucault. Silveira (2013), por exemplo, ao analisar os discursos oficiais da WADA-AMA acerca do doping no esporte, explorando, especialmente, as questões de gênero e sexualidade vinculadas às tecnologias contemporâneas, destaca que os principais aspectos veiculados pela WADA-AMA se referem, sobretudo, às questões de saúde e do incentivo à prática de atividades físicas, configurando, portanto, uma forma de governo sobre os corpos das atletas baseado na premissa eminentemente política do biopoder.

Tais aspectos reforçam o caráter contingente e esparso das relações de poder e de governo de sujeitos e corpos no tecido social. As relações aqui analisadas acerca das ações da WADA-AMA no controle e regulação dos atletas se inserem nesse escopo, qual seja, de novas formas de gerenciamento das ações de sujeitos, o que conforma, ao fim, estratégias de governo destes atletas. A construção de dispositivos que gerenciem as ações dos atletas de alto rendimento não apenas os regula, mas os aloca em determinadas posições de sujeito, condiciona-os a determinados grupos sociais. Nesse caso, estes grupos são organizados não apenas pelas marcações biológicas, mas, sobretudo, pelas alterações biológicas que promovem a partir das tecnologias da vida contemporâneas, borrando as 
tradicionais categorizações entre natural/cultural/artificial, constituindo-se num novo grupo emergente regido pelo uso das tecnologias em seus corpos, criando novas formas de sociabilidade, a biossociabilidade. Entrementes, esta biossociabilidade aqui aludida é regida e composta, também, pela própria organização que a rastreia e regula: a WADA-AMA.

\section{GOVERNO DA VITALIDADE DA PERFORMANCE ESPORTIVA}

É preciso enfatizar que as considerações aqui elencadas sobre as formas de regulação dos corpos e dos sujeitos atletas só fazem sentido se pudermos analisá-las enquanto constituintes de um novo coletivo ou comunidade de indivíduos, que se baseia, especialmente, no controle de suas capacidades vitais. É nessa direção que, ao regular as políticas de aumento do desempenho de atletas de alto rendimento, a WADA-AMA acaba, concomitantemente, conformando-os enquanto um grupo social específico e, a partir disso, compondo parte desse grupo o qual regula. Esse grupo social, submetido ao controle da vitalidade, está numa nova ordem de saber-poder, pois os elementos de biossociabilidade que os constituem são os diversos incrementos que potencializam suas performances, em especial, aqueles relacionados aos "princípios de informação" ou os que se encontram no nível da "molecularização". É evidente que outros recursos, que atuam no plano "molar" de melhoria do rendimento esportivo, continuam atuando, mas, mesmo esses, embora vistos a "olho nu", são igualmente alvos de regulação e controle, constituindo-se também em vetores da biossociabilidade.

Portanto, o que está em pauta na conformação da biossociabilidade dos atletas de alto rendimento não é tanto o nível em que as aplicações ocorrem nos seus corpos, sejam elas "informacionais", "moleculares" ou "molares", mas o próprio exercício de conhecimento, controle e regulação exercido pela Agência. Em suma, é o próprio "governo da vitalidade da performance esportiva", a partir das inúmeras estratégias utilizadas pela WADA-AMA, que acaba por conformar uma coletividade específica, baseada na vitalidade em si mesma. Este grupo biossocial são os atletas de elite.

É preciso que se atente para as diferentes formas de regulação dos corpos na arena esportiva de alto rendimento, na medida em que estas de algum modo também orientam o nosso fazer não atlético nas diferentes instâncias sociais em que estamos sujeitos. Conforme já mencionado a partir de Welsch (2001) a condição ontológica dos atletas de alto rendimento pertence ao mesmo registro que a nossa. Desse modo, ao estarem regulados e organizados em coletividades biossociais a partir do uso, controle, mecanismos de ameaça e de punição, é possível derivar que também o somos. Ou ao menos, potencialmente poderemos ser. 
George Saliba Manske é Doutor em Educação (PPCEDU/UFRCS). Professor dos cursos de Educação Física, da Residência Multiprofissional em AB e SF, do Mestrado em Saúde e Gestão do Trabalho e do Mestrado em Educação da Universidade do Vale do Itajaí (UNIVALI).

\section{REFERÊNCIAS BIBLIOGRÁFICAS}

FAUSTO-STERLING, Anne

2001/02 "Dualismos em duelo". Cadernos Pagu, n. 17/18: 9-79.

FOUCAULT, Michel

1988 História da sexualidade I: a vontade de saber. Tradução de Maria T. C. Albuquerque e ]. A. Guilhon Albuquerque. Rio de Janeiro, Edições Craal.

1995 "O Sujeito e o Poder". In DREYFUS, Hubert; RABINOW, Paul. Michel Foucault-Uma trajetória filosófica: para além do estruturalismo e da hermenêutica. Rio de Janeiro, Forense Universitária.

1997 "Do governo dos vivos". In . Resumo dos cursos do Collège de France (1970-1982). Tradução de Andréa Daher; consultoria, Roberto Machado. Rio de Janeiro, Jorge Zahar Ed., pp. 99-106.

1997b "É preciso defender a sociedade". In . Resumo dos cursos do Collège de France (1970-1982). Tradução de Andréa Daher; consultoria, Roberto Machado. Rio de Janeiro, Jorge Zahar Ed., pp. 69-78.

FRAGA, Alex Branco

2006 Exercício da informação: governo dos corpos no mercado da vida ativa. Campinas, SP, Autores associados.

HUMANITYPLUS

Disponível em http://humanityplus.org/. Acesso em 02 de julho de 2015.

LIMA, Homero Luís Alves

2004 Do corpo-máquina ao corpo-informação: o pós-humano como horizonte biotecnológico. Recife, tese de doutorado, Universidade Federal de Pernambuco. 
MACHADO E SILVA, Regina Coeli

2008 "Um rosto para vestir, um corpo para usar: narrativa

literária e biotecnológica". Horizontes antropológicos,

Porto Alegre, ano 14, n. 29:151-188.

MARCELLINO, Nelson Carvalho (org.)

2013 Legados de megaeventos esportivos. Campinas, Papirus, 1ed, v.1.

MIAH, Andy

2008 Atletas geneticamente modificados: ética biomédica, doping genético e esporte. São Paulo, Phorte.

RABINOW, Paul

1999 "Artificialidade e iluminismo: da sociobiologia à biossociabilidade". In Antropologia da razão. Rio de Janeiro, Relume Dumará, pp.135-157.

RABINOW, Paul e ROSE, Nikolas

2006 "O conceito de biopoder hoje". Política \& Trabalho Revista de Ciências Sociais, n. 24: 27-57

ROSE, Nikolas

2001 "Como se deve fazer a história do eu". Educaçãoe Realidade. Porto Alegre, v. 26, n. 1: 33-57.

2013 A política da própria vida: biomedicina, podere subjetividade no Século XXI. São Paulo, Paulus.

SIBILIA, Paula

2002 O homem pós-orgânico-corpo, subjetividade e tecnologias digitais. Rio de Janeiro, Relume Dumará.

SILVEIRA, Viviane

2013 Tecnologias e a mulher atleta: novas possibilidades de corpose sexualidades no esporte contemporâneo. Florianópolis, tese de doutorado, Universidade Federal de Santa Catarina.

SLOTERDIJK, Peter

2006 "El hombre operable. Notas sobre el estado ético de La tecnología génica". Revista Observaciones Filosóficas. Antropologia, Mayo. 
TRABAL, Patrick

2013 "E se os esportistas que se dopam quisessem 'fazer direito'?". Movimento. Porto Alegre, v. 19, n. 04: 11-43.

WELSCH, Wolfgang

2001 "Esporte - visto esteticamente e mesmo como arte?". In ROSENFIELD, D. (org.). Ética e estética. Rio de Janeiro, Jorge Zahar Ed., pp. 142-165.

\section{Fontes}

WORLD ANTI-DOPING AGENCY - AGÊNCIA

MUNDIAL ANTIDOPING (WADA-AMA)

2014 Disponível em http://www.wada-ama.org/.

Acesso em 02 de julho de 2014.

2002 WADANEWS, n.1, fevereiro, 2002. Disponível em

http://www.wada-ama.org/. Acesso em 02 de julho de 2014.

2002 WADANEWS, n.2, junho, 2002. Disponível em

http://www.wada-ama.org/. Acesso em 02 de julho de 2014.

2003 PLAYTRUE, n. 1, primavera, 2003. Disponível em

http://www.wada-ama.org/. Acesso em 02 de julho de 2014.

2007 PLAYTRUE, n. 1, 2007. Disponível em

http://www.wada-ama.org/. Acesso em 02 de julho de 2014.

2009 PLAYTRUE, n. 2, 2009. Disponível em

http://www.wada-ama.org/. Acesso em 02 de julho de 2014. 


\section{ABSTRACT}

Taking the Olympics to be held in Tokyo in 2020 as a starting point for problematizations about high-performance athletes government, I discuss the construction of bio-social communities as subjects of control strategies. Birth assumption that biotech today's conditions alter traditional notions of natural, cultural and artificial, and that these conditions are openings for emerging forms of social regulation, exemplified in this study in athletes and high performance sports. In conducting these discussions analyze the ways in which the World Anti-Doping Agency (WADA-AMA) prepares and performs management actions of the sporting vitality, primarily through the excerpts and statements present in the Play True magazine. It is considered that contemporary biotechnological able to change the human make up new forms of socialization, marked by an increase in vital capacity by changing the traditional understanding of body and nature, requiring new forms of government bodies.

Recebido em 9 de março de 2016. Aceito em 28 de setembro de 2017.

\section{KEYWORDS}

Covernment, Biosociability, Sports, Athletes, Culture 